\title{
Only natural local odours allow homeward orientation in homing pigeons released at unfamiliar sites
}

\author{
Anna Gagliardo ${ }^{1} \cdot$ Enrica Pollonara ${ }^{1}$ Martin Wikelski
}

\begin{abstract}
According to the olfactory navigation hypothesis, birds are able to exploit the spatial distribution of environmental odourants to determine the direction of displacement and navigate from non-familiar locations. The so-called "olfactory activation hypothesis" challenged the specific role of olfactory cues in navigation by suggesting that olfactory stimuli only activate a navigational system that is based on non-olfactory cues, predicting that even artificial odourants alone are sufficient to allow unimpaired navigation. In this experiment, we compared tracks of experimental birds exposed to different olfactory stimuli before being made anosmic at the release site prior to release. One group of pigeons was exposed to purified air enriched with artificial odourants, while a second group was exposed to environmental air. The birds stimulated with artificial nonsense odourants displayed several behavioural differences from both untreated controls and anosmic pigeons exposed to environmental air prior to release: nonsense odourants birds were unable to determine the home direction, they mostly flew within a space outside the homeward oriented quadrant, and they flew shorter distances on the day of release. Our data failed to support a mere activational role of olfactory stimuli in navigation, and are consistent with the olfactory navigation hypothesis.
\end{abstract}

Keywords Olfaction · Homing pigeon · Navigation · GPS tracking · Anosmia

\section{Introduction}

The "olfactory navigation hypothesis" was formulated by Floriano Papi (Papi et al. 1971) to explain that (1) homing pigeons subjected to olfactory nerve section could not find home from an unfamiliar location and that (2) exposure to winds blowing at the home area is needed for the development of their navigational abilities (Wallraff 1966). According to this hypothesis, pigeons develop an olfactory map by learning the wind-borne odours in association with the direction of the winds blowing at home. When displaced to a non-familiar location, they are able to determine the

Anna Gagliardo anna.gagliardo@unipi.it

1 Department of Biology, University of Pisa, Via Volta 6, 56126 Pisa, Italy

2 Department for Migration and Immuno-ecology, Max Planck Institute for Ornithology, Am Obstberg 1, 78315 Radolfzell, Germany direction of displacement on the basis of the prevalent local odourants at the release site, by recalling the direction from which these odourants were blown at the home area (see Papi 1986; Wallraff 2005, 2015; Gagliardo 2013 for reviews on the subject). Extensive research on pigeon navigation accumulated a considerable amount of data consistently supporting a specific role of local environmental odours in pigeon navigation (see Wallraff 2005 for refs). Nevertheless, it has been recently proposed that olfactory stimulation during transportation is needed for activating a navigational mechanism based on unspecified non-olfactory cues (Jorge et al. 2009, 2010). The proponents of this hypothesis (olfactory activation hypothesis) reported that birds released in anosmic conditions showed unimpaired vanishing bearing distributions provided that they had been exposed to odourants during the outward journey, regardless whether these odourants were "map" odourants (potentially learned in association with the wind directions) or novel artificial non-sense odourants (Jorge et al. 2009, 2010). In addition to navigational tests, Jorge et al. (Jorge et al. 2014) reported the immediate early gene expression in the brain of pigeons exposed to environmental air, artificial odourants and purified air, suggesting that the dorsolateral portion of 
the hippocampus might be involved in the activation of the navigational system triggered by any olfactory stimulation. However, this interpretation is inconsistent with a number of lesion studies showing that hippocampal ablations do not affect the pigeons' ability to determine the direction of displacement (Bingman et al. 2005; Gagliardo et al. 2014).

The priming role of olfactory stimuli has been challenged by data from a GPS tracking study showing that pigeons exposed to artificial nonsense odourants during transportation and released after nasal anaesthesia showed impaired homeward orientation. In contrast, birds exposed to environmental air during transportation and at the release site before being released under nasal anaesthesia were able to determine the home direction (Gagliardo et al. 2011). The method used by Gagliardo et al. (2011) to deliver artificial odourants during transportation (one injection of $50 \mathrm{ml}$ of fully saturated air with one odorant every $20 \mathrm{~min}$ ) was criticised by Phillips and Jorge (2014), claiming that the olfactory stimulus was too strong and not delivered continuously. According to these authors, Gagliardo et al. (2011) failed to obtain results consistent with those reported in Jorge et al. (2009, 2010), because of an unsuitable olfactory stimulation. It is worth noting that detailed information on the amount of odorant used was not reported by Jorge et al. in their first two papers on the subject (Jorge et al. 2009, 2010). Only later, detailed information on the stimulation procedure were given (JBP's personal communication in the Royal Institute Navigation Forum; Phillips and Jorge 2014).

The present experiment reports the effect on pigeon navigational performances of olfactory stimulation with artificial odourants during transportation, achieved with a procedure similar to that adopted by Jorge et al. (2009, 2010).

\section{Materials and methods}

\section{Experimental procedures}

Sixty-three inexperienced adult pigeons hatched at the Arnino field station (Latitude 43 $39^{\prime} 26^{\prime \prime} \mathrm{N}$; Longitude $\left.10^{\circ} 18^{\prime} 14^{\prime \prime} \mathrm{E}\right)$, Pisa, Italy, were used in the study. Their age ranged between 5 and 9 months. The pigeons were raised as free flyers and were not subjected to training releases. At least 2 weeks prior to the experimental releases, all the birds were equipped with a PVC dummy weight, similar in dimension and weight to the GPS data logger they would be carrying, to accustom them to flying with a load. The dummy was attached to the pigeons' back by means of a Velcro strip glued on the feathers, which had been trimmed. To track the released pigeons, we used GSM GPS loggers (FT-T1C-STPc-176: AgoraSmart@multi-functional module; weight $25 \mathrm{~g}$ ) and Mobile Action IgotU (20 g) GPS loggers only in the first release for $\mathrm{C}$ and $\mathrm{ZnC}$ groups (see below). The sampling rate was 1 fix every minute. The loggers were set so to automatically switch off after the sunset and switch on before sunrise, to save the power of the battery. The positional fixes stored by a GPS data logger include latitude, longitude, speed and time of recording. Both kind of GPS loggers stored positional data, but only the GPS GSM loggers transmitted the data.

In each release, three groups of pigeons subjected to three different treatments were tested. A sketch of the experimental procedure is shown in Fig. 1. The C-pigeons $(n=21)$ were transported in a crate to the release site and released without further manipulation after at least $2 \mathrm{~h}$ from the arrival to the release site. We chose not to perform any nasal washing with physiological solution to the $\mathrm{C}$ birds,
Fig. 1 Sketch of the experimental procedure. Details in the "Materials and methods" section
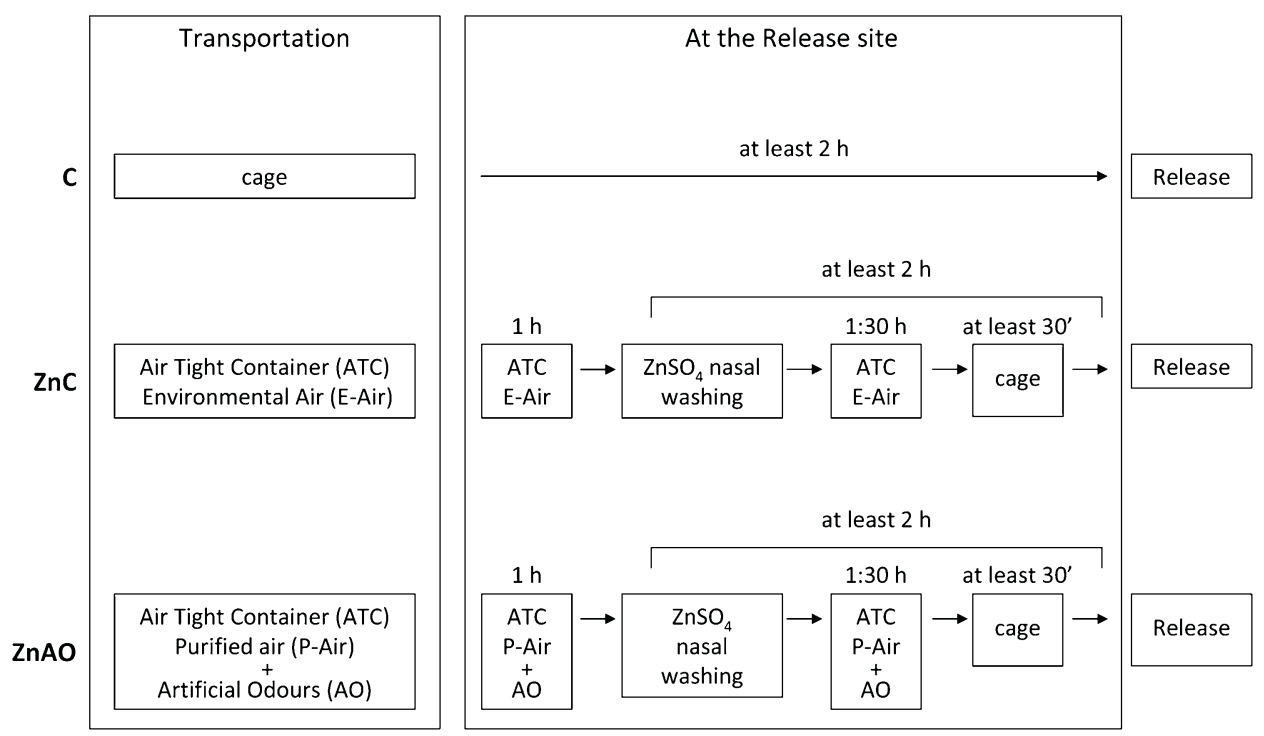
because this treatment might temporary affect the ability to smell, while we wanted to measure the response of birds fully able to smell any time during the experiment. The $\mathrm{ZnC}$ pigeons $(n=22)$ were transported to the release site in an airtight container ventilated with environmental air by an aspirator; once arrived at the release site these birds were allowed to smell the environmental air at the release site for at least $1 \mathrm{~h}$ before being made anosmic; the birds were released at least $2 \mathrm{~h}$ after the anosmia treatment, which consisted in washing their olfactory mucosa with a $4 \%$ zinc sulphate solution (Guilford et al. 1998); the pigeons were taken out of the airtight container at least $30 \mathrm{~min}$ before being released. The third group, the $\mathrm{ZnAO}$ pigeons $(n=22)$, was transported inside an airtight container ventilated by air filtered through an active charcoal filter to remove most of the natural odourants contained in the air. A by-pass applied to the tube carrying filtered air to the containers was connected to an apparatus for the olfactory stimulation composed by a tube system connected to four $50 \mathrm{ml}$ vials each containing a small piece of cotton embedded with $100 \mu$ of an odorant (lavender, eucalyptus, rose, thyme). The access of the air in and out of each vial was regulated by two taps. During the displacement and at the release site, for at least $1 \mathrm{~h}$, an experimenter delivered one odorant every $5 \mathrm{~min}$, by opening/closing the two taps regulating the flux in and out of a vial. The birds were exposed in sequence to lavender, lavender and eucalyptus, eucalyptus, eucalyptus and rose, rose, rose and thyme, thyme, thyme and lavender, lavender and so on. After one hour of stimulation at the release site, the birds were made anosmic with zinc sulphate nasal washing; also the $\mathrm{ZnAO}$ pigeons were taken out of the airtight container at least $30 \mathrm{~min}$ before being released; the release took place at least $2 \mathrm{~h}$ after the zinc sulphate treatment.

Three releases took place from Bolgheri (home direction $336^{\circ}$, home distance $53 \mathrm{~km}$ ) under sunny conditions, with no or light wind. Each pigeon was released singly, alternating between treatments. The time of the day at which the birds were released ranged from the late morning to the early afternoon: $\mathrm{C}$ between 10:58 and 14:27, $\mathrm{ZnC}$ between 11:11 and 15:35, ZnAO 11:24 and 15:10.

\section{Quantitative analyses and statistical procedures}

In the track analysis, the initial fixes of the track closer than $1 \mathrm{~km}$ radius from the release site were excluded from the analysis. For each track, we calculated the individual mean vector averaging the directions taken by the bird while moving from one point to the next at the recorded speed higher than $5 \mathrm{~km} / \mathrm{h}$. For each track, the distribution of the directions taken by the bird was tested for randomness with the $\mathrm{V}$ test. The number of significantly oriented tracks in the three groups where compared with the Chi square goodness of fit test. The mean vector distributions of the three groups of birds were tested for randomness with the one sample Hotelling test (Batschelet 1981). Comparisons on the orientation performances of the three groups were made by applying the two sample Hotelling test (Batschelet 1981).

For each track, we calculated the Homing Efficiency Index (HEI) that takes into account whether a bird approaches or gets away from home during its flight (see Gagliardo et al. 2016 for details) at 30, 60, 90, 120, 150, 180 min of flight. The HEIs of the three groups at the different times were compared with the two Way RM ANOVA, while the HEI calculated on the whole track has been compared with the Kruskall-Wallis test. We used the one way ANOVA to compare the percentage of fixes of the tracks of the three groups of birds located within the home quadrant $\left(291^{\circ}-021^{\circ}\right)$ to evaluate differences in spatial choices in the three groups while trying to reach home.

Differences in homing performances were assessed with the Kruskall-Wallis test applied to the following categories: birds homed on the day of release, for which the homing speed has been computed, birds homed on the day after the release, birds homed later and birds lost.

To highlight possible non-specific effects of the zinc sulphate treatment prior to release we analysed the behaviour of the birds on the day of the release. In particular, we analysed the virtual vanishing bearing distributions (the direction of the birds from the release site at $2 \mathrm{~km}$ from it), the number of stops per km of track, the percentage of the time spent sitting on the total time of GPS recording, and the number of kilometres flown. The virtual vanishing bearing distribution was tested for randomness with the $\mathrm{V}$ test, and compared with the Watson $U^{2}$ test (Batschelet 1981). The number of stops per $\mathrm{km}$ of track, the percentage of the time spent sitting, and the number of kilometres flown were compared among groups with the one way ANOVA. Multiple comparisons were performed with the Student-Newman-Keuls Method (Zar 1984).

\section{Results}

The orientation data of all the recorded tracks available (some GSM GPS failed to record the tracks) are reported in Tables 1, 2 and 3, for the $\mathrm{C}, \mathrm{ZnC}$ and $\mathrm{ZnAO}$ birds, respectively. As in the first release both $\mathrm{C}$ and $\mathrm{ZnC}$ were provided with IgotU loggers, we were unable to obtain tracks from the lost birds. Therefore, for this release only the homed $\mathrm{ZnAO}$ birds were included in the between-group comparison. The mean recording period (from the time of release up to when the battery run out of power) of the loggers placed on the $\mathrm{C}, \mathrm{ZnC}$ and $\mathrm{ZnAO}$ birds was about 23, 35, and $30 \mathrm{~h}$, respectively. No difference in the recording period between $\mathrm{ZnC}$ and $\mathrm{ZnAO}$ emerged ( $t$ test $p>0.1$ ). 
Table 1 Orientation of $\mathrm{C}$ birds

\begin{tabular}{llllllllr}
\hline Bird code & Date & $r$ & $\alpha$ & hc & \multicolumn{1}{l}{$n$} & $V$ test & HEI & HD \\
\hline C 044490 & $21 / 08 / 2013$ & 0.08 & $004^{\circ}$ & +0.07 & 153 & ns & +0.34732 & 16 \\
C 044505 & $21 / 08 / 2013$ & 0.49 & $340^{\circ}$ & +0.49 & 154 & $p<0.001$ & +0.46882 & 1 \\
C 096465 & $21 / 08 / 2013$ & 0.46 & $131^{\circ}$ & -0.42 & 185 & ns & -0.83155 & 8 \\
C 096486 & $21 / 08 / 2013$ & 0.38 & $338^{\circ}$ & +0.38 & 184 & $p<0.001$ & +0.41170 & 2 \\
C 043989 & $31 / 08 / 2013$ & 0.72 & $335^{\circ}$ & +0.72 & 93 & $p<0.001$ & +0.71650 & 2 \\
C 044357 & $31 / 08 / 2013$ & 0.48 & $333^{\circ}$ & +0.48 & 188 & $p<0.001$ & +0.40710 & 2 \\
C 044368 & $31 / 08 / 2013$ & 0.70 & $336^{\circ}$ & +0.70 & 112 & $p<0.001$ & +0.69999 & 1 \\
C 044401 & $31 / 08 / 2013$ & 0.59 & $336^{\circ}$ & +0.59 & 142 & $p<0.001$ & +0.54807 & 1 \\
C 096455 & $31 / 08 / 2013$ & 0.79 & $338^{\circ}$ & +0.79 & 86 & $p<0.001$ & +0.80625 & 2 \\
C 044332 & $04 / 09 / 2013$ & 0.06 & $033^{\circ}$ & +0.03 & 178 & $\mathrm{~ns}$ & +0.39675 & 30 \\
C 044355 & $04 / 09 / 2013$ & 0.23 & $324^{\circ}$ & +0.22 & 159 & $p<0.001$ & +0.38730 & 10 \\
C 044361 & $04 / 09 / 2013$ & 0.59 & $331^{\circ}$ & +0.59 & 119 & $p<0.001$ & +0.66812 & 2 \\
C 044421 & $04 / 09 / 2013$ & 0.63 & $341^{\circ}$ & +0.63 & 114 & $p<0.001$ & +0.65793 & 2 \\
C 044477 & $04 / 09 / 2013$ & 0.76 & $330^{\circ}$ & +0.76 & 92 & $p<0.001$ & +0.80279 & 1 \\
C 096469 & $04 / 09 / 2013$ & 0.85 & $333^{\circ}$ & +0.85 & 72 & $p<0.001$ & +0.88899 & 1 \\
\hline
\end{tabular}

For each bird track (Bird code), the mean vector length $(r)$ and mean direction $(\alpha)$, homeward component (hc), number of fixes considered in the analysis (n), homing efficiency index (HEI), the day on which the bird homed (HD, the homing day corresponds to 1 if the bird homed on the day of release and so on; lost means that the bird never returned) are reported in the table; significance level of the $\mathrm{V}$ test is reported (ns corresponds to $p>0.05$ )

Table 2 Orientation of $\mathrm{ZnC}$ birds

\begin{tabular}{lllllllll}
\hline Bird code & Date & $r$ & $\alpha$ & hc & $n$ & $V$ test & HEI & HD \\
\hline ZnC 044349 & $21 / 08 / 2013$ & 0.37 & $335^{\circ}$ & +0.37 & 146 & $p<0.001$ & +0.43091 & 2 \\
ZnC 044522 & $21 / 08 / 2013$ & 0.23 & $343^{\circ}$ & +0.23 & 198 & $p<0.001$ & +0.31911 & 24 \\
ZnC 043981 & $21 / 08 / 2013$ & 0.45 & $342^{\circ}$ & +0.45 & 163 & $p<0.001$ & +0.45211 & 2 \\
ZnC 044390 & $31 / 08 / 2013$ & 0.18 & $330^{\circ}$ & +0.18 & 136 & $p<0.01$ & +0.01718 & Lost \\
ZnC 044416 & $31 / 08 / 2013$ & 0.59 & $339^{\circ}$ & +0.59 & 165 & $p<0.001$ & +0.35398 & 3 \\
ZnC 044417 & $31 / 08 / 2013$ & 0.19 & $342^{\circ}$ & +0.19 & 220 & $p<0.001$ & +0.05684 & Lost \\
ZnC 096452 & $31 / 08 / 2013$ & 0.21 & $330^{\circ}$ & +0.21 & 129 & $p<0.001$ & +0.07360 & Lost \\
ZnC 096454 & $31 / 08 / 2013$ & 0.04 & $289^{\circ}$ & +0.03 & 109 & $n s$ & -0.00018 & Lost \\
ZnC 044406 & $31 / 08 / 2013$ & 0.84 & $336^{\circ}$ & +0.84 & 95 & $p<0.001$ & +0.81066 & 2 \\
ZnC 044257 & $04 / 09 / 2013$ & 0.12 & $339^{\circ}$ & +0.12 & 164 & $p<0.05$ & +0.31663 & 10 \\
ZnC 044347 & $04 / 09 / 2013$ & 0.21 & $338^{\circ}$ & +0.21 & 127 & $p<0.001$ & +0.07429 & Lost \\
ZnC 044370 & $04 / 09 / 2013$ & 0.25 & $337^{\circ}$ & +0.25 & 241 & $p<0.001$ & +0.14368 & Lost \\
ZnC 044397 & $04 / 09 / 2013$ & 0.04 & $184^{\circ}$ & -0.04 & 92 & $n s$ & -0.00522 & Lost \\
ZnC 044404 & $04 / 09 / 2013$ & 0.11 & $320^{\circ}$ & +0.11 & 150 & $p<0.05$ & +0.00116 & Lost \\
ZnC 044409 & $04 / 09 / 2013$ & 0.11 & $187^{\circ}$ & -0.09 & 64 & $n s$ & -0.00757 & Lost \\
ZnC 096484 & $04 / 09 / 2013$ & 0.51 & $333^{\circ}$ & +0.51 & 120 & $p<0.001$ & +0.58700 & 2 \\
\hline
\end{tabular}

Explanations as in Table 1
Representative tracks of the behaviour of each experimental group of birds are reported in Fig. 2 (see Supplementary Material for the other tracks). All the tracks are deposited in Movebank (http://www.movebank.org, https:// doi.org/10.5441/001/1.dn1b937k).

The number of birds displaying an oriented movement according to the $\mathrm{V}$ test was significantly different in the three groups $\left(\chi^{2}\right.$ goodness of fit test, $p<0.05 ; 12 \mathrm{C}, 13$ $\mathrm{ZnC}$ and $8 \mathrm{ZnAO}$ birds displayed an oriented movement out of 15, 16 and 18 pigeons, respectively). In particular, both $\mathrm{C}$ and $\mathrm{ZnC}$ birds were significantly more likely to display an oriented movement compared to the $\mathrm{ZnAO}$ pigeons $(p<0.05)$, while no difference emerged between the C and the $\mathrm{ZnC}$. It is worth noting that the three $\mathrm{ZnAO}$ birds excluded from the comparison for the reasons explained above displayed a non-oriented movement according to the $\mathrm{V}$ test (see Table 3 for details). 
Table 3 Orientation of $\mathrm{ZnAO}$ birds

\begin{tabular}{llllrrlll}
\hline Bird code & Date & $r$ & $\alpha$ & hc & $n$ & $V$ test & HEI & HD \\
\hline ZnAO 044254* & $21 / 08 / 2013$ & 0.07 & $233^{\circ}$ & -0.02 & 241 & ns & -0.06187 & Lost \\
ZnAO 044291 & $21 / 08 / 2013$ & 0.79 & $331^{\circ}$ & 0.79 & 42 & $p<0.001$ & +0.94791 & 6 \\
ZnAO 044335 & $21 / 08 / 2013$ & 0.22 & $345^{\circ}$ & 0.22 & 66 & $p<0.01$ & +0.21609 & 2 \\
ZnAO 044388* & $21 / 08 / 2013$ & 0.09 & $251^{\circ}$ & 0.01 & 28 & ns & -0.00921 & Lost \\
ZnAO 044420* & $21 / 08 / 2013$ & 0.13 & $354^{\circ}$ & 0.12 & 82 & ns & -0.00013 & Lost \\
ZnAO 044478 & $21 / 08 / 2013$ & 0.64 & $336^{\circ}$ & 0.64 & 122 & $p<0.001$ & +0.63584 & 9 \\
ZnAO 044265 & $31 / 08 / 2013$ & 0.37 & $313^{\circ}$ & 0.34 & 16 & $p<0.05$ & +0.89769 & 29 \\
ZnAO 044330 & $31 / 08 / 2013$ & 0.08 & $291^{\circ}$ & 0.06 & 83 & ns & +0.00426 & Lost \\
ZnAO 044350 & $31 / 08 / 2013$ & 0.16 & $323^{\circ}$ & 0.16 & 121 & $p<0.05$ & +0.38788 & 32 \\
ZnAO 044358 & $31 / 08 / 2013$ & 0.38 & $330^{\circ}$ & 0.38 & 122 & $p<0.001$ & +0.26216 & Lost \\
ZnAO 044395 & $31 / 08 / 2013$ & 0.08 & $302^{\circ}$ & 0.07 & 178 & $\mathrm{~ns}$ & +0.00034 & Lost \\
ZnAO 044474 & $31 / 08 / 2013$ & 0.12 & $287^{\circ}$ & 0.08 & 104 & $\mathrm{~ns}$ & +0.00071 & Lost \\
ZnAO 096458 & $31 / 08 / 2013$ & 0.25 & $197^{\circ}$ & -0.19 & 126 & $\mathrm{~ns}$ & -0.14679 & Lost \\
ZnAO 044287 & $04 / 09 / 2013$ & 0.12 & $181^{\circ}$ & -0.11 & 255 & $\mathrm{~ns}$ & -0.00539 & Lost \\
ZnAO 044345 & $04 / 09 / 2013$ & 0.10 & $216^{\circ}$ & -0.05 & 180 & $\mathrm{~ns}$ & -0.02297 & Lost \\
ZnAO 044372 & $04 / 09 / 2013$ & 0.02 & $120^{\circ}$ & -0.02 & 180 & $\mathrm{~ns}$ & -0.00273 & Lost \\
ZnAO 044373 & $04 / 09 / 2013$ & 0.09 & $330^{\circ}$ & 0.09 & 89 & $\mathrm{~ns}$ & +0.00440 & Lost \\
ZnAO 044375 & $04 / 09 / 2013$ & 0.37 & $334^{\circ}$ & 0.37 & 187 & $p<0.001$ & +0.40352 & 2 \\
ZnAO 044403 & $04 / 09 / 2013$ & 0.04 & $200^{\circ}$ & -0.03 & 234 & $\mathrm{~ns}$ & -0.00063 & Lost \\
ZnAO 044405 & $04 / 09 / 2013$ & 0.05 & $255^{\circ}$ & 0.01 & 222 & $\mathrm{~ns}$ & +0.00004 & Lost \\
ZnAO 096473 & $04 / 09 / 2013$ & 0.58 & $337^{\circ}$ & 0.58 & 121 & $p<0.001$ & +0.63047 & 2 \\
\hline
\end{tabular}

Bird code: the tracks not included in the between-group comparison are marked with an asterisk. Other explanations as in Table 1
The three groups of birds displayed mean vector distributions significantly different from random (see Fig. 3, Hotelling test $p<0.001$ for all groups). However, the orientation of the birds was affected by the exposure to environmental odourants prior to release. In fact, both $\mathrm{C}$ and $\mathrm{ZnC}$ pigeons oriented in a direction close to the home direction (the $95 \%$ confidence limits of their mean vector distribution included the home direction), while the $\mathrm{ZnAO}$ birds oriented in a direction significantly different from the home direction $(\mathrm{C}$, $n=15 r=0.46, \alpha=337^{\circ}, 95 \%$ CI $333^{\circ}-350^{\circ} ; \mathrm{ZnC} n=16$, $r=0.26, \alpha=335^{\circ}, 95 \%$ CI $325-339^{\circ} ; \mathrm{ZnAO} n=18, r=0.19$, $\alpha=322^{\circ}, 95 \% \mathrm{CI} 255^{\circ}-333^{\circ} ; \mathrm{ZnAO}$ including all tracks available $n=21, r=0.17, \alpha=321^{\circ}, 95 \%$ CI $\left.259^{\circ}-333^{\circ}\right)$. The $\mathrm{ZnAO}$ mean vector distribution $(n=18)$ turned out to be significantly different from both the C (Two Samples Hotelling Test, $F=4.782 p<0.05)$ and, more importantly, from the $\mathrm{ZnC}(F=4.044, p<0.05)$ distributions. No difference emerged from the comparison between the $\mathrm{C}$ and $\mathrm{ZnC}$ distributions $(F=3.249, p>0.5)$.

The whole length of the recorded tracks in the three groups of birds was comparable (mean length $\mathrm{C} 112.0 \pm 55.8 \mathrm{~km}$; $\mathrm{ZnC} 106.5 \pm 39.2 \mathrm{~km}$; ZnAO $103.6 \pm 40.2 \mathrm{~km}$; One Way ANOVA, $F=0.145 p>0.5)$.

The homing efficiency index for every $30 \mathrm{~min}$ of active flight is shown in Fig. 4. The two way RM ANOVA revealed a significant difference between the treatments $\left(F_{2,45}=\right.$
4.305, $p<0.02$ ). The multiple comparison performed with the Tukey test showed that the $\mathrm{C}$ birds displayed a HEI significantly greater than that of the $\mathrm{ZnAO}$ pigeons $(p<0.05)$, but comparable to that observed for the $\mathrm{ZnC}$ birds $(p>0.1)$, while no significant difference between the $\mathrm{ZnC}$ and the ZnAO pigeons emerged (Tukey test, $p>0.5$ ). There was a significant difference between flight times $\left(F_{5,174}=17.324\right.$, $p<0.001$ ), particularly because at $30 \mathrm{~min}$ the HEI was smaller compared to the subsequent times. No significant interaction between the treatment and the active flight time emerged $\left(F_{10,174}=0.955, p>0.1\right)$. Consistently, the Kruskall-Wallis test revealed a significant difference in the HEI calculated on the whole tracks $(p=0.001$; median HEI: C 0.548, ZnC 0.109, ZnAO 0.000524; see Tables 1, 2, 3 for the HEI calculated on the whole track for each bird). In particular, a difference between the $\mathrm{C}$ and $\mathrm{ZnAO}$ was detected (Dunn's test, C vs ZnAO $p<0.001$ ), while no differences in the other comparisons emerged ( $\mathrm{C}$ vs $\mathrm{ZnC}$ and $\mathrm{ZnC}$ vs $\mathrm{ZnAO}, p>0.05)$. However, percentage of fixes located within the home quadrant was significantly different in the three groups of birds (one way ANOVA, $F_{2,46}$ $=6.793, p=0.003$; mean percentage of fixes within the home quadrant: C 77.1 $\pm 24.6, \mathrm{ZnC} 60.9 \pm 29.6, \mathrm{ZnAO}$ $40.5 \pm 30.6$; Fig. 5). In fact, the ZnAO birds displayed a significantly lower percentage of fixes located in the home quadrant, compared to both $\mathrm{C}$ and, more importantly, $\mathrm{ZnC}$ 


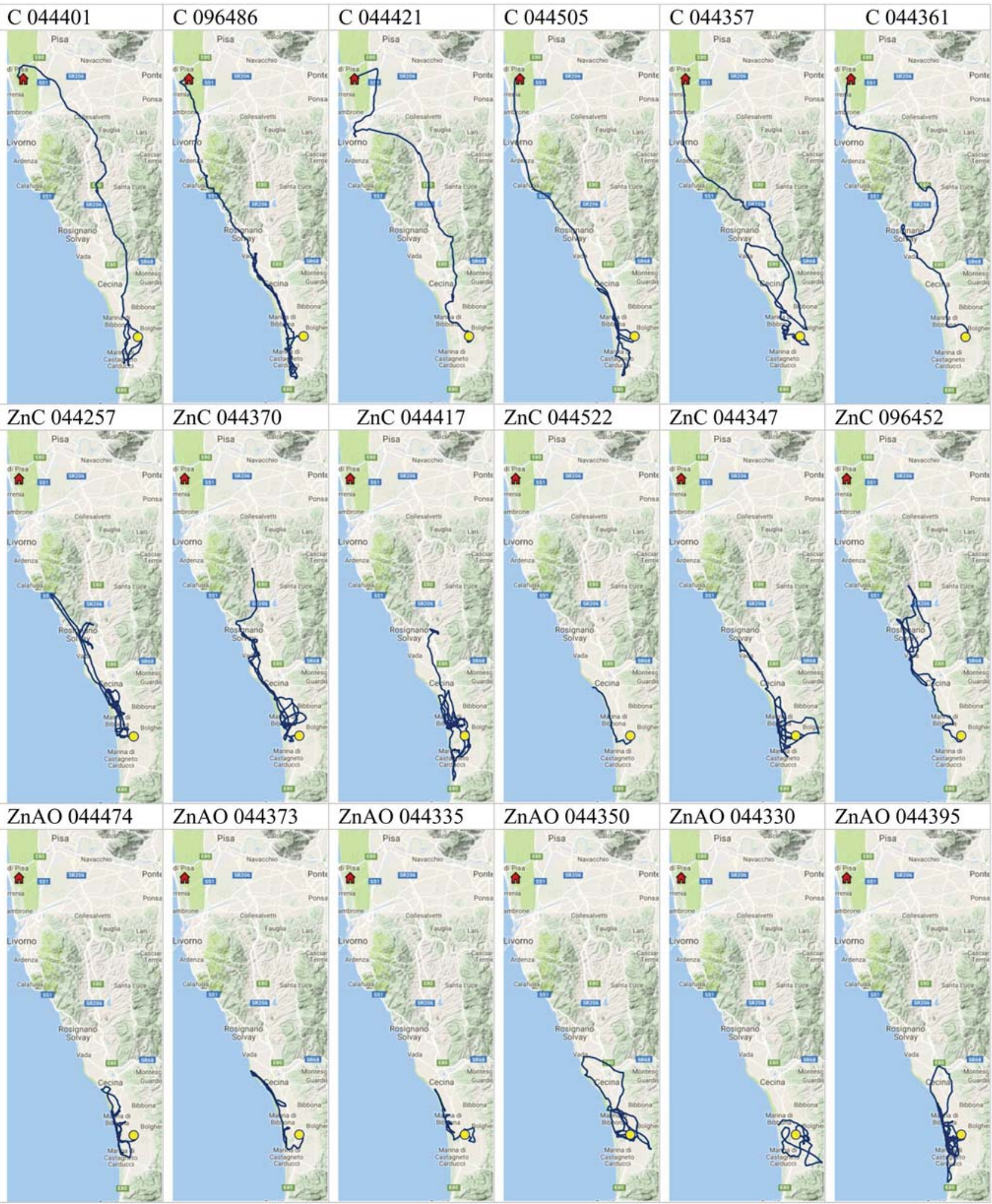

Fig. 2 Representative tracks of $\mathrm{C}, \mathrm{ZnC}$ and $\mathrm{ZnAO}$ birds. The tracks have been selected on the basis of the median values of the homeward component (hc) and/or the homing efficiency index (HEI) calculated on the whole track. See "Materials and methods", and Tables 1, 2 and 3 for details. The red symbol and the yellow circle represent the home location and release site, respectively 
Fig. 3 Mean vector distributions of the three groups of birds. Each mean vector represent the individual mean bird orientation calculated on the whole track. The symbol at the periphery of the circles represents the orientation of the mean vectors. Confidence ellipses of the second-order distributions are reported (Hotelling test, significance values $p<0.05, p<0.01$; $p<0.001)$. The dotted lines represent the confidence limits of the mean vector distribution

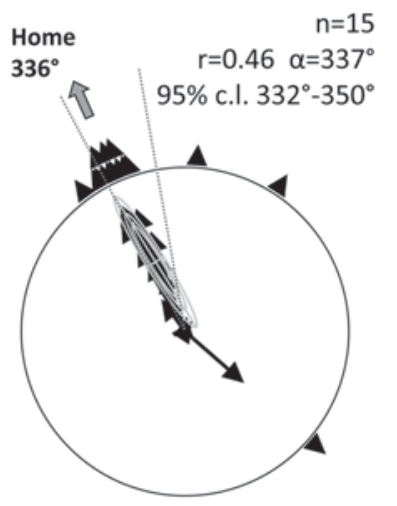

C

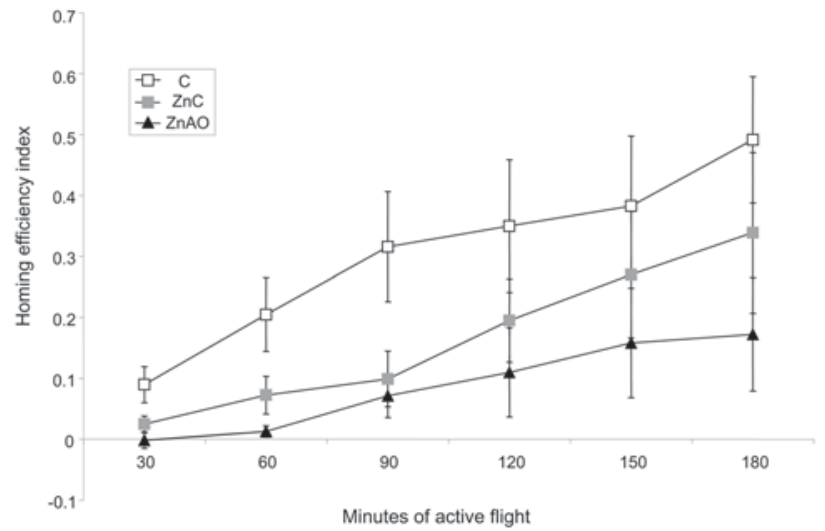

Fig. 4 Mean Homing Efficiency Index every 30 min of active flight. Standard errors bars are represented

(Student-Newman-Keuls Method, $\mathrm{ZnAO}$ vs $\mathrm{C}$ and $\mathrm{ZnAO}$ vs $\mathrm{ZnC} p<0.01$ and $p<0.05$, respectively, $\mathrm{C}$ vs $\mathrm{ZnC} p>0.1$ ), while no difference between $\mathrm{C}$ and $\mathrm{ZnC}$ emerged.

The homing performance of the three groups of birds was significantly different according to the Kruskall-Wallis test $(p<0.001)$. The $\mathrm{C}$ birds were significantly faster and proficient at homing than both the $\mathrm{ZnC}$ and the $\mathrm{ZnAO}$ pigeons (Dunn's test, $p<0.001$ in both comparisons). Five $\mathrm{C}, 15 \mathrm{ZnC}$ and $15 \mathrm{ZnAO}$ never returned to their loft (see Tables 1, 2, 3 for other details on the birds' homing performance).

As the zinc sulphate treatment was applied prior to release (Gagliardo et al. 2016) rather than on the day before, as reported in most other experiments (see Wallraff 2005 for refs), we tried to evaluate the possible non-specific effect of the zinc sulphate by conducting an analysis of the behaviour of the birds on the day of the release. The analysis on the virtual vanishing bearing distribution (orientation of the birds with respect to the release site at about $2 \mathrm{~km}$ from it; see Fig. 6) of the three groups of birds showed that only the $\mathrm{C}$ birds displayed a significantly oriented distribution according to the $\mathrm{V}$ test $(p<0.05)$,
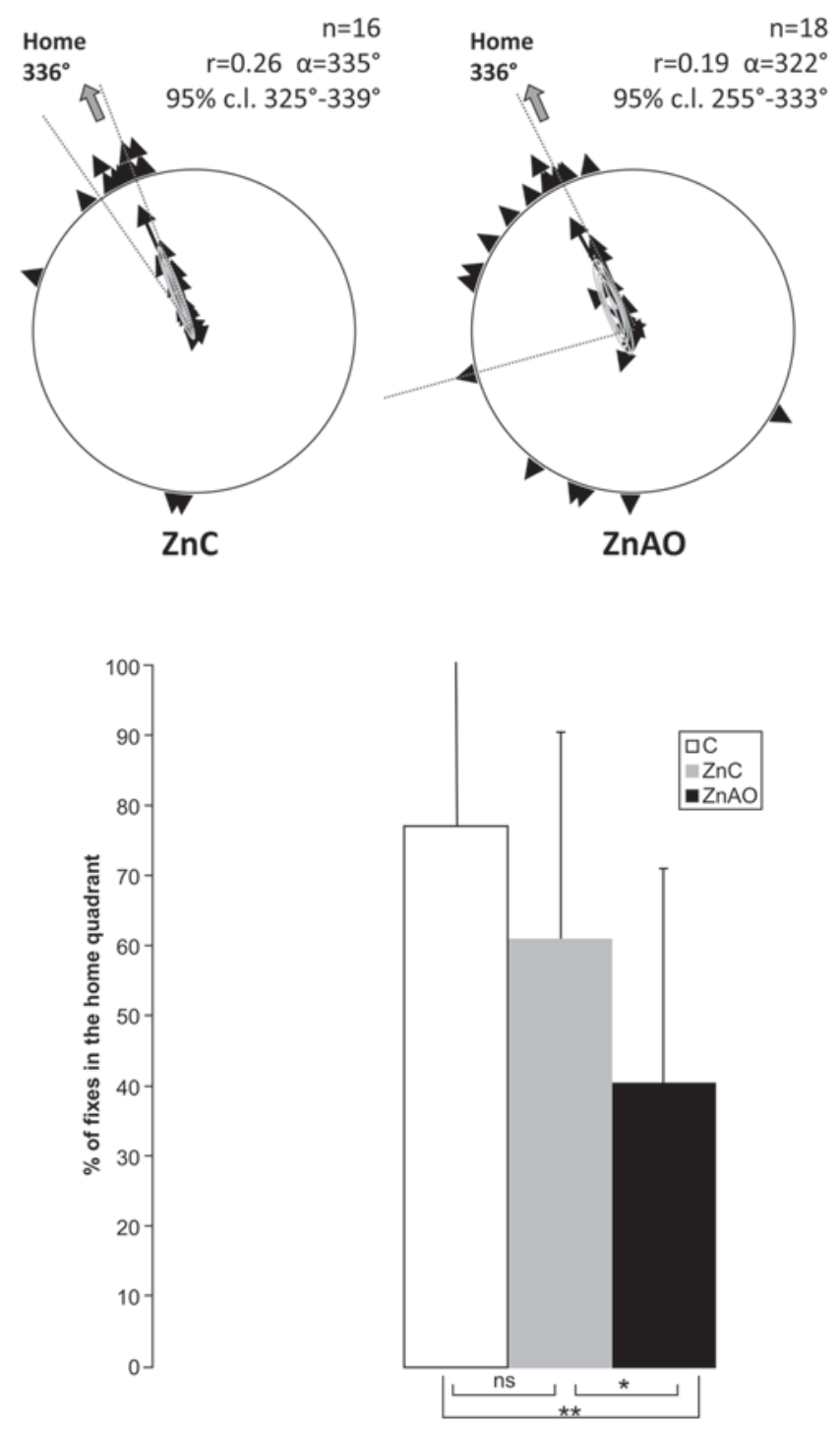

Fig. 5 Mean percentage of fixes of the tracks of the three groups of birds falling within the home quadrant $\left(291^{\circ}-021^{\circ}\right)$. Error bars represent standard deviations. ${ }^{*} p<0.05$; ${ }^{* *} p<0.01$, ns $p>0.1$; further explanation in the "Results"

that takes into account the expected direction $(\mathrm{C}, n=15$, $r=0.53, \alpha=296^{\circ}, p<0.05$ according to the $\mathrm{V}$ test; $\mathrm{ZnC}$, $n=16, r=0.76, \alpha=216^{\circ}, p>0.05 ; \mathrm{ZnAO}, n=18, r=0.64$, $\alpha=205^{\circ}, p>0.05$ ). However, the mean vector distributions relative to the section of tracks recorded on the day of the release, displayed the same pattern as the whole tracks distributions. In fact, the second-order mean vector distribution of the three groups of birds were significantly oriented according to the Hotelling test (C, $n=15$, $r=0.41 \alpha=332^{\circ}, p<0.001 ; \mathrm{ZnC} n=16, r=0.23 \alpha=332^{\circ}$, $p<0.01$; ZnAO $n=18 r=0.17 \alpha=275^{\circ}, p<0.05$ ). However, differences in homeward orientation emerged in the three groups already on the day of release. In fact, both C and $\mathrm{ZnC}$ confidence limits included the home direction $(\mathrm{C}$ 
Fig. 6 Virtual vanishing bearing distributions of the three groups of pigeons. In each diagram, the outer arrow represents the home direction; the inner arrow represents the mean vector; $r$ mean vector length, $\alpha$ mean vector direction, $h c$ homeward component. Further explanation in the text

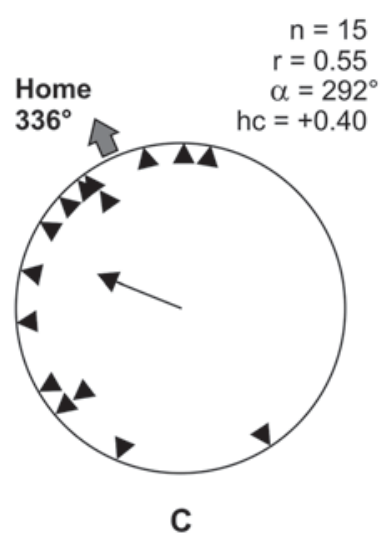

$318^{\circ}-338^{\circ}$, $\mathrm{ZnC} 277^{\circ}-350^{\circ}$ ), while the $\mathrm{ZnAO}$ birds oriented in a direction significantly different from the home direction (CI $\left.215^{\circ}-302^{\circ}\right)$. It is worth noting that already on the first day after release, the $\mathrm{ZnAO}$ birds displayed a significantly different mean vector distribution from both the $\mathrm{C}$ and the $\mathrm{ZnC}$ pigeons (Two Sample Hotelling Test, $\mathrm{ZnAO}$ vs $\mathrm{C} F=8.606 p<0.01 ; \mathrm{ZnAO}$ vs $\mathrm{ZnC} F=4.308$ $p<0.025)$, while no difference between $\mathrm{C}$ and $\mathrm{ZnC}$ distributions was found ( $F=1.862 p>0.1)$. Therefore, while at $2 \mathrm{~km}$ from the release site both anosmic groups displayed a similar impaired homeward orientation, the movements recorded on the first day of test showed that only those birds exposed to natural environmental odourants were able to orient homeward. In conclusion, while a non-specific effect of the nasal washing might have produced an initial impairment in homeward orientation at $2 \mathrm{~km}$ from the release site, the inability of the $\mathrm{ZnAO}$ to correct their orientation towards home can be hardly attributed to a non-specific effect of the zinc sulphate treatment.

The three groups of birds showed a comparable number of stops (mean number of stops per kilometre; C $0.213 \pm 0.17$, $\mathrm{ZnC} 0.26 \pm 0.18, \mathrm{ZnAO} 0.33 \pm 0.42$; one way ANOVA $p>0.5)$ and spent a comparable time sitting expressed as percentage of the total time of recording during the first day of test $(\mathrm{C} 68.0 \pm 8.7, \mathrm{ZnC} 73.7 \pm 12.6, \mathrm{ZnAO} 73.5 \pm 16.1$; one way ANOVA $p>0.1)$. Interestingly, a significant difference emerged in the length of the path flown on the day of release in the three groups of birds (Fig. 7; mean path length in $\mathrm{km}$ : C 61.2 $\pm 20.4 ; \mathrm{ZnC} 44.0 \pm 21.2 ; \mathrm{ZnAO} 28.5 \pm 18.0$; one way ANOVA $F=11.185 p<0.001)$. A post hoc analysis showed a statistical difference in all comparisons (Student-Neumann-Keuls Method, C vs ZnAO $p<0.001$; both $\mathrm{ZnC}$ vs $\mathrm{C}$ and $\mathrm{ZnC}$ vs $\mathrm{ZnAO} p<0.05)$. In conclusion, both anosmic groups on the day of release flown significantly shorter path compared to controls. However, the reduction of the flight path length cannot be entirely attributed to a possible non-specific effect of the zinc sulphate treatment, as the $\mathrm{ZnAO}$ birds flew along significantly shorter path compared to the $\mathrm{ZnC}$.
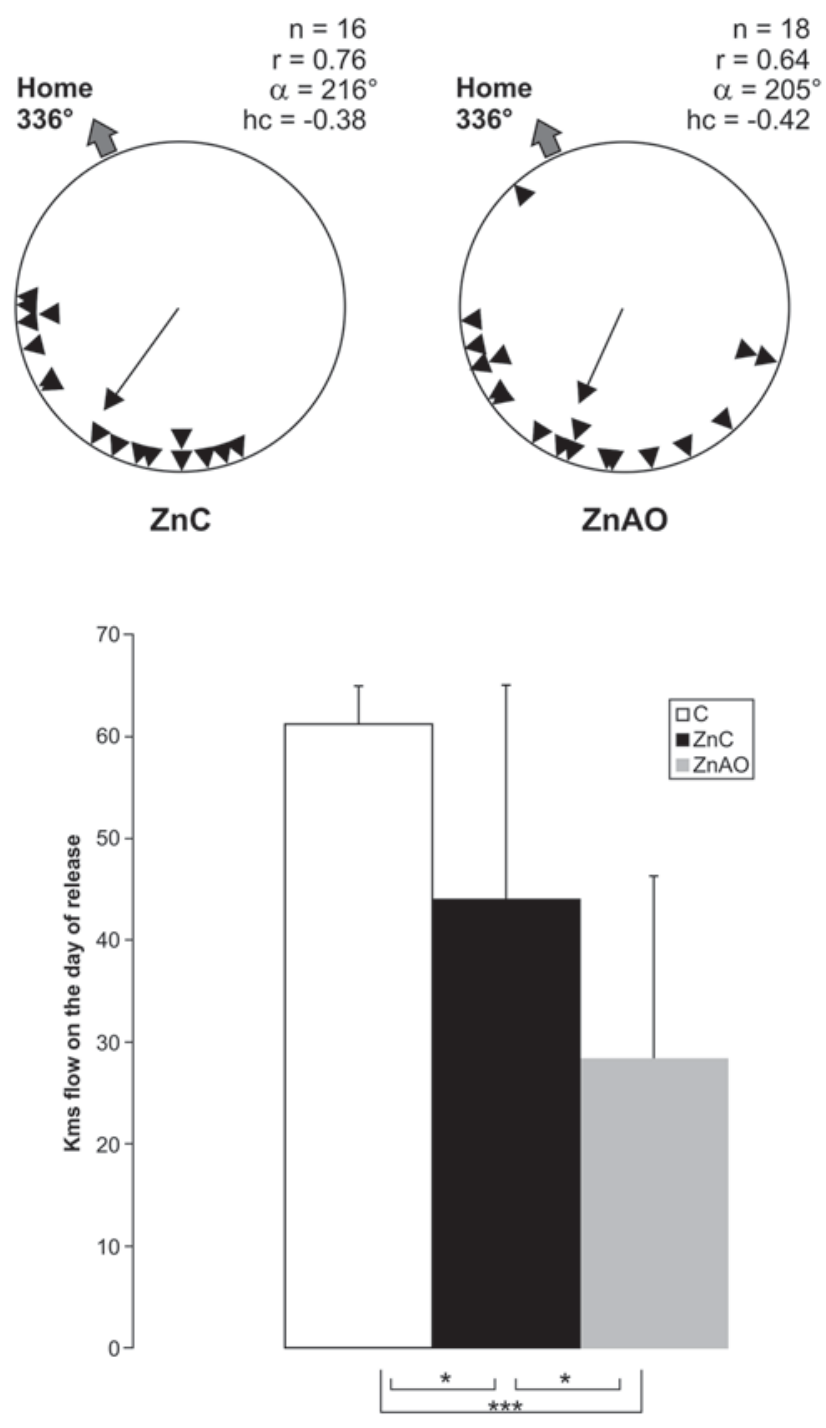

Fig. 7 Mean kilometres flown by the three groups of birds on the day of release. Error bars represent standard deviations. ${ }^{*} p<0.05$; $* * * p<0.001$; further explanation in the "Results"

\section{Discussion}

\section{Specific role of environmental olfactory information in homeward orientation}

The ability of the birds to determine the home direction on the basis of local olfactory information has been reported by a variety of studies (Wallraff and Foà 1981; Benvenuti and Wallraff 1985; Wallraff et al. 1992; Gagliardo et al. 2001, 2016). However, odour-based navigation in homing pigeons has been challenged by the idea that olfactory stimuli, rather than providing positional information, might have an activational role on a navigational system based on non-olfactory cues. According to the olfactory 
activation hypothesis, unimpaired navigational abilities of anosmic pigeons are expected, provided that during the outward journey their olfactory system was stimulated by any olfactory stimuli, regardless of whether they consist of natural environmental local odourants or artificial novel odourants. The results reported here failed to confirm the olfactory activation hypothesis, as birds made anosmic by washing their olfactory mucosa with a zinc sulphate solution prior release, were unable to orient homeward if prevented to smell local environmental odours, although stimulated with artificial novel odourants during transportation ( $\mathrm{ZnAO})$. By contrast, birds exposed to local environmental odours both during the outward journey and at the release site, and made anosmic prior to release displayed a mean vector distribution significantly different from that exhibited by the ZnAO pigeons, and more importantly, homeward oriented.

\section{Effects of zinc sulphate nasal washing prior release on birds' navigational performances}

Compared to local anaesthesia of the olfactory mucosa which only works for relatively short and unpredictable duration, the zinc sulphate nasal washing produces a long lasting anosmia, by inducing necrosis of the olfactory neurons (Cancalon 1982). A full regeneration of the olfactory mucosa occurs thanks to the maturation and differentiation of the basal cells, which is likely to be completed after a few months (Bedini et al. 1976). We chose to use the latter method to better control the exposure of the pigeons to olfactory stimuli during the whole experiment, and therefore evaluate the birds' navigational performances during the whole GPS tracking period. We also tracked the birds rather than recording only their initial directions at vanishing, because, as also observed in the present experiment (see virtual vanishing bearing distributions), behavioural differences between experimental groups might only emerge at distances further than $2 \mathrm{~km}$ from the release site. Maybe the contradiction between the results of the tracking tests on the olfactory activation hypothesis [the present data and those reported in Gagliardo et al. (2011)] and the evidence reported by Jorge et al. (2010) might be due to differences in data sampling (tracking vs vanishing bearing recording).

As expected according to the olfactory navigation hypothesis, both anosmic groups ( $\mathrm{ZnC}$ and $\mathrm{ZnAO}$ ) were equally impaired at homing, although they had been exposed to olfactory stimulation during their outward journey. These results are consistent with a previous GPS tracking study, showing that pigeons treated with zinc sulphate at the release site were impaired at homing, but were able to orient homeward, only provided that they had been allowed to smell natural local odours both during transportation and at the release site (Gagliardo et al. 2016). Interestingly, pigeons transported in purified air were unable to determine the home direction and on the whole oriented in a direction significantly different from home (Gagliardo et al. 2016), similarly to what observed in the $\mathrm{ZnAO}$ group tested in the present work.

It has been previously suggested (Gagliardo et al. 2016) that the birds exposed to environmental air before zinc sulphate nasal washing $(\mathrm{ZnC})$, although homeward oriented, were unable to eventually reach home because the olfactory map needs to be consulted on the way for a successful homing. In the present work, we analysed the percentage of fixes of the tracks distributed in the home quadrant, to assess whether there was a difference between the two anosmic groups in the spatial distribution of their home searching movements. Interestingly, both groups exposed to environmental air ( $\mathrm{C}$ and $\mathrm{ZnC})$ displayed a comparable percentage of fixes distributed in the home quadrant, and in both cases significantly higher than that exhibited by the $\mathrm{ZnAO}$ birds. In conclusion, also this analysis suggested that the $\mathrm{ZnAO}$ birds seemed not to be aware of their position with respect to home.

During previous studies, the zinc sulphate nasal washing was applied to the birds at least a day prior to release (Guilford et a. 1998; Benvenuti et al. 1992; Gagliardo et al. 2001, 2013; Pollonara et al. 2015), while in both the previous (Gagliardo et al. 2016) and the present study the anosmic groups were subjected to zinc sulphate treatment at the release site, at least $2 \mathrm{~h}$ before release. For this reason, one may argue that a general, non-specific effect of the treatment might have occurred. The results of the analysis on the behaviour of the birds on the day of release suggested that the treatment might have affected the initial directional decision of the anosmic birds. In fact, both $\mathrm{ZnC}$ and $\mathrm{ZnAO}$ were unable to orient homeward at vanishing (at $2 \mathrm{~km}$ from the release site), in contrast to the unmanipulated control birds. However, it is worth noting that after this initial impairment, the $\mathrm{ZnC}$ were able to orient homeward already on the day of the release, while the $\mathrm{ZnAO}$ took a direction significantly different from the home direction. Consistently to what was previously reported (Gagliardo et al. 2016), the zinc sulphate nasal washing prior to release does not seem to have significantly affected the number of stops per kilometre and the time spent sitting. Although the length of the whole track recorded of the three groups of birds was comparable, the flight path flown by the birds on the day of release was significantly different in the three groups. Although anosmic groups displayed shorter tracks than unmanipulated controls on the day of release, it is unlikely that this reduction in the flight path might be entirely due to a non-specific effect of the anosmia treatment, because the lengths of the tracks recorded on the day of release were significantly different between the $\mathrm{ZnC}$ and the $\mathrm{ZnAO}$ birds. Anosmic birds exposed to environmental air $(\mathrm{ZnC})$ flew longer paths on 
the day of release compared to birds exposed to artificial odourants $(\mathrm{ZnAO})$. This difference suggests that the exposure to navigational olfactory cues before release in anosmic condition encouraged the birds to fly longer distances to search home.

\section{Olfactory navigation hypothesis vs olfactory activation hypothesis}

In the present study, we reported that the anosmic birds stimulated with artificial nonsense odourants prior to release displayed impaired homeward orientation, as expected according to the prediction of the olfactory navigation hypothesis. While the environmental olfactory information seems to provide pigeons with sufficient information for homeward orientation, the stimulation with artificial nonsense odourants failed to do so. The reported results contradict the olfactory activation hypothesis, according to which pigeons stimulated with artificial odourants were expected to show unimpaired navigational performances. If the olfactory activation hypothesis were correct, we would have observed both anosmic pigeons stimulated with any type of olfactory stimuli to find home, because smells should trigger the neural processes underlying navigation mechanisms based on non-olfactory information. This was not observed, as both anosmic groups were impaired at homing. The incompatibility of the olfactory activation hypothesis with previous experimental data, as well as its general implausibility have been discussed in a detailed and comprehensive review (Wallraff 2014). Nevertheless, it is worth pointing out one additional inconsistent aspect of this hypothesis. In the view of its proponents (Jorge et al. 2009, 2010; Phillips and Jorge 2014), the exposure to non-home odourants is necessary for alerting the birds that they have been displaced far from home. In a recent study, Jorge and colleagues (Jorge et al. 2014) claimed that such olfactory stimulation would activate the hippocampal formation which, according to their view, should play a central role in activating the pigeons' navigational mechanism. As a matter of fact, the hippocampal formation is not involved in the operation of the navigational map in homing pigeons (Bingman et al. 2005), because hippocampal ablation does not impair homeward orientation (Bingman et al. 1984), even though hippocampal lesioned birds are slower at homing than control birds (Bingman et al. 1988). Furthermore, tracking studies reported that hippocampal ablated birds are unimpaired in long distance navigation (Gagliardo et al. 2014), and that the impairment in their homing time is due to the difficulty of the lesioned birds in visual familiar landmark-based navigation (Bingman and Mench 1990; Gagliardo et al. 2014), needed for localising the loft within the home area in the last phase of their homing process (Gagliardo et al. 2007). We therefore suggest that the immediate early gene expression in the hippocampal formation following olfactory stimulation reported by Jorge et al. (Jorge et al. 2014) cannot be ascribed to an olfactory activation process of a navigational mechanism.

In the last few years, the use of tracking methods in displacement experiments on birds subjected to sensory manipulation supported the role of olfactory cues in wild birds' navigation both for homing to their nest (Gagliardo et al. 2013; Pollonara et al. 2015) and during migration (Holland et al. 2009; Wikelski et al. 2015). Recently, a study on spontaneous movements of non-displaced Scopoli's shearwaters made anosmic while incubating eggs, ruled out the non-specific effect of anosmia treatment on their foraging and reproductive behaviour (Padget et al. 2017), while confirming the specific effect of olfactory deprivation on the navigational strategies used by birds for homing. In fact, anosmic shearwaters turned out to adopt coastal navigation, rather than moving in open ocean as birds with an intact sense of smell did.

In conclusion, the olfactory activation hypothesis, besides being contradictory (see detailed comments in (Gagliardo et al. 2013; Wallraff 2014)) failed to be confirmed when tested with GPS tracking experiments (Gagliardo et al. 2011, and the results reported here), which in contrast provided further evidence for the critical role of the sense of smell in avian navigation.

Acknowledgements Our experiment has been conducted in accordance with the Italian law on animal welfare (Permit number 8630/2011). We are grateful to Tim Guilford for participating to the release performed on the 21st of August 2013. Fabio Chini and Andrea Guidi greatly helped in preparing and performing the experiment. Daniele Santerini helped in the figures preparation.

\section{References}

Batschelet E (1981) Circular statistics in biology. Academic Press, London

Bedini C, Fiaschi V, Lanfranchi A (1976) Olfactory nerve reconstitution in homing pigeon after resection-ultrastructural and electrophysiological data. Arch Ital Biol 114:1-22

Benvenuti S, Wallraff HG (1985) Pigeon navigation: site simulation by means of atmospheric odours. J Comp Physiol A 156:737-746

Benvenuti S, Ioalè P, Gagliardo A, Bonadonna F (1992) Effects of zinc sulphate-induced anosmia of homing behaviour of pigeons. Comp Biochem Physiol A 103:519-526

Bingman VP, Mench JA (1990) Homing behavior of hippocampus and parahippocampus lesioned pigeons following short-distance releases. Behav Brain Res 40:227-238

Bingman VP, Bagnoli P, Ioalè P, Casini G (1984) Homing behavior of pigeons after telencephalic ablations. Brain Behav Evol 24:94-108

Bingman VP, Ioalè P, Casini G, Bagnoli P (1988) Hippocampal ablated homing pigeons show a persistent impairment in the time taken to return home. J Comp Physiol A 163:559-563

Bingman VP, Gagliardo A, Hough GE, Ioalè P, Kahan NC, Siegel JJ (2005) The avian hippocampus, homing in pigeons and the 
memory representation of large scale space. Integr Comp Biol 45:555-564

Cancalon P (1982) Degeneration and regeneration of olfactory cells induced by $\mathrm{ZnSO}_{4}$ and other chemicals. Tissue Cell 14:713-733

Gagliardo A (2013) Forty years of olfactory navigation in birds. J Exp Biol 216:2165-2171

Gagliardo A, Odetti F, Ioalè P (2001) Relevance of visual cues for orientation at familiar sites by homing pigeons: an experiment in a circular arena. Proc Roy Soc Lond B 268:1-6

Gagliardo A, Ioalè P, Savini M, Lipp H-P, Dell'Omo G (2007) Finding home: the final step of the pigeons' homing process studied with a GPS data logger. J Exp Biol 210:1132-1138

Gagliardo A, Ioalè P, Filannino C, Wikelski M (2011) Homing pigeons only navigate with intact environmental odours: a test of the olfactory activation hypothesis with GPS data loggers. PlosOne 6:e22385

Gagliardo A, Bried J, Lambardi P, Luschi P, Wikelski M, Bonadonna F (2013) Oceanic navigation in Cory's shearwaters: evidence for a crucial role of olfactory cues for homing after displacement. J Exp Biol 216:2798-2805

Gagliardo A, Pollonara E, Coppola VJ, Santos CD, Wikelski M, Bingman VP (2014) Evidence for perceptual neglect of environmental features in hippocampal-lesioned pigeons during homing. Eur $\mathbf{J}$ Neurosci 40:3102-3110

Gagliardo A, Pollonara E, Wikelski M (2016) Pigeon navigation: exposure to environmental odours prior to release is sufficient for homeward orientation, but not for homing. J Exp Biol 219:2475-2480

Guilford T, Gagliardo A, Chappell J, Bonadonna F, Burt de Pereira T, Holland R (1998) Homing pigeons use olfactory cues for navigation in England. J Exp Biol 201:895-900

Holland RA, Thorup K, Gagliardo A, Bisson I, Knecht E, Mizrahi D, Wikelski M (2009) Testing the role of sensory systems in the migratory heading of a songbird. J Exp Biol 212:4065-4071

Jorge PE, Marques AM, Phillips JB (2009) Activational rather than navigational effects of odors on homing of young pigeons. Curr Biol 19:650-654

Jorge PE, Marques AM, Phillips JB (2010) Activational effects of odours on avian navigation. Proc Roy Soc Lond B 277:45-49

Jorge PE, Phillips JB, Goncalves A, Marques AM, Nemec P (2014) Odours stimulate neuronal activity in the dorsolateral area of the hippocampal formation during path integration. Proc Roy Soc B 281:20140025

Padget O, Dell'Ariccia G, Gagliardo A, González-Solís J, Guilford $\mathrm{T}$ (2017) Anosmia impairs homing orientation but not foraging behaviour in free-ranging shearwaters. Sci Rep 7:9668

Papi F (1986) Pigeon navigation: solved problems and open questions. Monit Zool Ital (N S) 20:471-517

Papi F, Fiore L, Fiaschi V, Benvenuti S (1971) The influence of olfactory nerve section on the homing capacity of carrier pigeons. Monit Zool Ital (N S) 5:265-267

Phillips JB, Jorge PE (2014) Olfactory navigation: failure to attempt replication of critical experiments keeps controversy alive. Reply to Wallraff Anim Behav 90:e7-e9

Pollonara E, Luschi P, Guilford T, Wikelski M, Bonadonna F, Gagliardo A (2015) Olfaction and topography, but not magnetic cues, control navigation in a pelagic seabird: displacements with shearwaters in the Mediterranean sea. Sci Rep 5:16486

Wallraff HG (1966) Über die Heimfindeleistung von Brieftauben nach Haltung in verschiedenartig abgeschirmten Volieren. Z Vergl Physiol 52:215-259

Wallraff HG (2005) Avian navigation: pigeon homing as a paradigm. Springer, Berlin

Wallraff HG (2014) Do olfactory stimuli provide positional information for home-oriented avian navigation? Anim Behav 90:e1-e6

Wallraff HG (2015) An amazing discovery: bird navigation based on olfaction. J Exp Biol 218:1464-1466

Wallraff HG, Foà A (1981) Pigeon navigation: charcoal filter removes relevant information from environmental air. Behav Ecol Sociobiol 9:67-77

Wallraff HG, Kiepenheuer J, Neumann MF, Sinsch U (1992) Microclimatic origin of inhaled air affects olfactory navigation of homing pigeons. Experientia 48:1153-1158

Wikelski M, Arriero E, Gagliardo A, Holland RA, Huttunen MJ, Juvaste R, Mueller I, Tertitski G, Thorup K, Wild M, Alanko M, Bairlein F, Cherenkov A, Cameron A, Flatz R, Hannila J, Hüppop O, Kangasniemi M, Kranstauber B, Penttinen M-L, Safi K, Semashko V, Schmid H, Wistbacka R (2015) True navigation in migrating gulls requires intact olfactory nerves. Sci Rep 5:17061

Zar JH (1984) Biostatistical analysis. Prentice-Hall, Englewood Cliffs 